\title{
Calcium/Calmodulin-Dependent Protein Kinase II Mediates Hippocampal Glutamatergic Plasticity During Benzodiazepine Withdrawal
}

\author{
Guofu Shen', Bradley J Van Sickle' and Elizabeth I Tietz ${ }^{*, 1,2}$ \\ 'Department of Physiology and Pharmacology, University of Toledo College of Medicine, Health Science Campus, Toledo, OH, USA; ${ }^{2}$ Department \\ of Neurosciences, University of Toledo College of Medicine, Health Science Campus, Toledo, OH, USA
}

\begin{abstract}
Benzodiazepine withdrawal anxiety is associated with potentiation of $\alpha$-amino-3-hydroxy-5-methyl-4-isoxazolepropionate receptor (AMPAR) currents in hippocampal CAI pyramidal neurons attributable to increased synaptic incorporation of GluAl-containing AMPARs. The contribution of calcium/calmodulin-dependent protein kinase II (CaMKII) to enhanced glutamatergic synaptic strength during withdrawal from I-week oral flurazepam (FZP) administration was further examined in hippocampal slices. As earlier reported, AMPAR-mediated miniature excitatory postsynaptic current (mEPSC) amplitude increased in CAI neurons from 1-and 2-day FZP-withdrawn rats, along with increased single-channel conductance in neurons from 2-day rats, estimated by non-stationary noise analysis. Input-output curve slope was increased without a change in paired-pulse facilitation, suggesting increased AMPAR postsynaptic efficacy rather than altered glutamate release. The increased mEPSC amplitude and AMPAR conductance were related to CaMKII activity, as intracellular inclusion of CaMKIINtide or autocamtide-2-related inhibitory peptide, but not scrambled peptide, prevented both AMPAR amplitude and conductance changes. mEPSC inhibition by I-naphthyl acetyl spermine and the negative shift in rectification index at both withdrawal time points were consistent with functional incorporation of GluA2-lacking AMPARs. GluAI but not GluA2 or GluA3 levels were increased in immunoblots of postsynaptic density (PSD)-enriched subcellular fractions of CAI minislices from I-day FZP-withdrawn rats, when mEPSC amplitude, but not conductance, was increased. Both GluAI expression levels and CaMKIl $\alpha$-mediated GluAI Ser ${ }^{831}$ phosphorylation were increased in PSD-subfractions from 2-day FZP-withdrawn rats. As phospho-Thr ${ }^{286} \mathrm{CaMKIl} \alpha$ was unchanged, CaMKIl $\alpha$ may be activated through an alternative signaling pathway. Synaptic insertion and subsequent CaMKIl $\alpha$-mediated Ser ${ }^{831}$ phosphorylation of GluAI homomers contribute to benzodiazepine withdrawal-induced AMPAR potentiation and may represent an important hippocampal pathway mediating both drug-induced and activity-dependent plasticity. Neuropsychopharmacology (2010) 35, 1897-1909; doi:I0.1038/npp.20I0.6I; published online 5 May 2010
\end{abstract}

Keywords: CAI neuron; CaMKIl; AMPA receptor; GluA subunits; GluR subunits; drug dependence

\section{INTRODUCTION}

Benzodiazepines, allosteric modulators of the $\mathrm{GABA}_{\mathrm{A}}$ receptor, are a safe, well-tolerated, and effective treatment for anxiety, insomnia, and seizures, yet carry some abuse liability, and signs of physical dependence may emerge after long-term use (Griffiths and Johnson, 2005). Although benzodiazepine tolerance has been associated primarily with $\mathrm{GABA}_{\mathrm{A}}$ receptor regulation (Bateson, 2002), mechanisms involving both GABAergic and glutamatergic systems have been proposed to underlie manifestations of benzodiazepine dependence (Allison and Pratt, 2003; Wafford,

\footnotetext{
*Correspondence: Professor El Tietz, Department of Physiology and Pharmacology, University of Toledo College of Medicine, University of Toledo Health Science Campus (formerly Medical University of Ohio), 3000 Arlington Avenue, Mailstop 1008, Toledo, OH 436।4, USA, Tel: + 419383 4170; Fax: + I 419383 287I,

E-mail: liz.tietz@utoledo.edu

Received 26 August 2009; revised 21 March 2010; accepted 2 April 2010
}

2005). In fact, pharmacological approaches using specific glutamate receptor antagonists to modify withdrawal phenomena suggested that activation of excitatory aminoacid receptors might be central to the expression of benzodiazepine physical dependence (Dunworth and Stephens, 1998; Koff et al, 1997; Van Sickle et al, 2004; Xiang and Tietz, 2007).

Abrupt withdrawal from prolonged benzodiazepine administration results in potentiation of $\alpha$-amino-3-hydroxy-5methyl-4-isoxazolepropionate receptor (AMPAR)-mediated synaptic currents associated with withdrawal anxiety (Van Sickle and Tietz, 2002; Xiang and Tietz, 2007). The amplitude of AMPAR-mediated miniature (m)EPSCs progressively increased in hippocampal CA1 pyramidal neurons from 1- and 2-day flurazepam (FZP)-withdrawn rats associated with a localized increase in AMPAR binding (Van Sickle et al, 2002, 2004) and an increase in glutamate efficacy (Song et al, 2007). Immunofluorescence and immunoblot studies revealed that GluA1 (GluR1; Collingridge et al, 2009) but not GluA2 (GluR2) subunit expression coupled with the enhancement of 
the GluA1 scaffolding protein, synapse-associated protein 97 may be responsible for the enhanced glutamate-elicited currents in CA1 neurons (Song et al, 2007; see also Izzo et al, 2001). The latter interpretation was further supported using postembedding immunogold electron microscopy (EM). GluA1 but not GluA2 immunoreactivity was increased at CA1 neuron asymmetric synapses (Das et al, 2008).

The GluA1 subunit, one of the two major hippocampal AMPAR subunits, has a long cytoplasmic carboxyl terminus, which undergoes phosphorylation by several kinases. GluA1 trafficking and phosphorylation contribute to activity-dependent synaptic plasticity (Derkach et al, 2007). In particular, a transient increase in GluA1 AMPARs (Plant et al, 2006) was detected as both a shift in the current rectification index in the presence of spermine analogs (Washburn and Dingledine, 1996) and by an alteration in AMPAR single-channel properties (Benke et al, 1998; Luthi et al, 2004). Calcium/calmodulin-dependent protein kinase II (CaMKII), one of the most abundant proteins in the postsynaptic density (PSD), is required for activity-dependent membrane incorporation of GluA1 (and GluA4) subunit-containing AMPARs (Esteban et al, 2003), and subsequent phosphorylation of GluA1-subunits at Ser ${ }^{831}$ enhancing single-channel conductance of GluA2-lacking AMPARs (Derkach et al, 1999; Oh and Derkach, 2005).

To further explore the contribution of CaMKII to AMPAR potentiation during benzodiazepine withdrawal, whole-cell mEPSCs were recorded in CA1 pyramidal neurons in hippocampal slices from rats withdrawn from 1-week oral FZP administration to evaluate AMPAR-mediated synaptic transmission and single-channel conductance by nonstationary noise analysis (NSNA). Input-output (I/O) relationships and paired-pulse facilitation (PPF) were used in conjunction to assess the contribution of pre- and postsynaptic mechanisms to enhanced AMPAR currents. A potent spermine analog was applied extracellularly to evaluate the contribution of GluA2-lacking, $\mathrm{Ca}^{2+}$-permeable receptors (Pellegrini-Giampietro, 2003; Washburn and Dingledine, 1996) to the transient, progressive increase in AMPAR potentiation during benzodiazepine withdrawal. Intracellular application of active and inactive CaMKII inhibitors was used to evaluate the function of CaMKII to modify AMPAR conductance. Immunoblots of PSDenriched subcellular fractions of CA1 minislices were used to evaluate the withdrawal-associated expression patterns of total and phosphorylated GluA1-3 and CaMKII $\alpha / \beta$ subunits. The findings suggest that insertion of GluA1 homomeric AMPARs and CaMKII-mediated phosphorylation of Ser $^{831}$ GluA1 coupled with enhanced hippocampal AMPAR conductance may represent one common feature among drug-induced and other activitydependent models of plasticity.

\section{MATERIALS AND METHODS}

\section{FZP-Withdrawal Model}

An FZP-dosing regimen was used, which reliably induces manifestations of both benzodiazepine tolerance and dependence in both juvenile and adult rats (Song et al, 2007; Van Sickle and Tietz, 2002; Van Sickle et al, 2004; Zeng and Tietz, 1999). Male Sprague-Dawley rats (Harlan,
Indianapolis, IN), postnatal (PN) day 36-42 at the time of study were handled in accordance with institutional and $\mathrm{NIH}$ guidelines and approved by the University of Toledo Institutional Animal Care and Use Committee. Rats were first adapted to the animal facility and to the $0.02 \%$ saccharin vehicle for 2-4 days, then offered FZP (provided by the National Institute of Drug Abuse Supply Program) in $0.02 \%$ saccharin vehicle for 1 week $(100 \mathrm{mg} / \mathrm{kg} \times 3$ days; $150 \mathrm{mg} / \mathrm{kg} \times 4$ days) as their sole source of drinking water, followed by 1 or 2 days of drug withdrawal. Daily water consumption was monitored to adjust the drug concentration to offer the desired dose. Rats that did not reach a weekly average of $120 \mathrm{mg} / \mathrm{kg} /$ day were excluded. FZPtreated rats received saccharin water during the withdrawal period. Matched control rats received the saccharin vehicle in parallel throughout the course of the study. All electrophysiological and immunochemical studies described were conducted with the experimenter blind to the experimental treatment groups.

\section{Hippocampal Slice Preparation}

After decapitation, the hippocampus was rapidly dissected and transverse dorsal hippocampal slices $(400 \mu \mathrm{m})$ were cut on vibratome (Ted Pella, Redding, CA) in ice-cold, pregassed, low-calcium artificial cerebrospinal fluid (ACSF) containing (in $\mathrm{mM}$ ) NaCl $120 ; \mathrm{KCl} 2.5 ; \mathrm{CaCl}_{2} 0.5 ; \mathrm{MgCl}_{2} 7.0$; $\mathrm{NaH}_{2} \mathrm{PO}_{4}$ 1.2; $\mathrm{NaHCO}_{3} 2$; D-glucose 20; ascorbate 1.3; pH 7.4. Slices were maintained at room temperature $\left(22^{\circ} \mathrm{C}\right)$ for $15 \mathrm{~min}$ in gassed low-calcium ACSF and then transferred to normal ACSF containing (in $\mathrm{mM}$ ) NaCl 119; $\mathrm{KCl} 2.5 ; \mathrm{CaCl}_{2}$ 1.8; $\mathrm{MgSO}_{4}$ 1.3; $\mathrm{NaH}_{2} \mathrm{PO}_{4}$ 1.25; $\mathrm{NaHCO}_{3}$ 26; D-glucose 10; $\mathrm{pH}$ 7.4. Slices were recovered at room temperature for $\geqslant 2 \mathrm{~h}$ in ACSF before electrophysiological recording. During recording, slices were perfused at a rate of $2.5 \mathrm{ml} / \mathrm{min}$ with gassed ACSF at room temperature.

\section{Whole-Cell Electrophysiological Recording}

For whole-cell AMPAR-mediated mEPSC recordings, hippocampal slices were continuously perfused with oxygenated ACSF and visualized on an upright Zeiss Axioskop. Blind whole-cell patch-clamp recordings from CA1 pyramidal neurons were made using borosilicate micropipettes (4-7 M , WPI, Sarasota, FL) containing (in $\mathrm{mM}$ ) Cs methanesulfonate 132.5; $\mathrm{CsCl}$ 17.5; HEPES 10; EGTA 0.2; $\mathrm{NaCl} 8$; Mg-ATP 2; $\mathrm{Na}_{3}$-GTP 0.3; QX-314 2; pH 7.2. Alternately, the CaMKII inhibitor autocamtide-2 (ACM), a CaMKII substrate (HKKALRRQETVDAL-OH, $5 \mu \mathrm{M}$, EMD Chemicals, Madison, WI) or the more potent, selective CaMKII inhibitor (Ishida et al, 1995) autocamtide-2-related inhibitory peptide (AIP, H-KKKLRRQEAFDAL-OH, $5 \mu \mathrm{M}$, EMD Chemicals) was added to the micropipette before mEPSC recordings. A control scrambled peptide (H-ELRKFQADLKRKA-OH) used at the same micropipette concentration was designed to disrupt both the basic C-terminal and hydrophobic N-terminal groups of AIP. The scrambled sequence was analyzed online using the blastp (protein-protein) suite in the National Center for Biotechnology Information BLAST tool (http://blast.ncbi.nlm. nih.gov/Blast.cgi), and no similar sequence was found in the current database. As it was more recently shown that CaMKI (Guire et al, 2008), as well as CaMKII (Esteban et al, 2003), can 
recruit AMPARs to the synapse, the intracellular effects of the most selective CaMKII inhibitor available, CaMKIINtide $(5 \mu \mathrm{M}$; Sanhueza et al, 2007), was also evaluated in several neurons from control and 2-day FZP-withdrawn rats. EPSCs were recorded under voltage clamp $\left(V_{\mathrm{H}}=-80 \mathrm{mV}\right)$ in the presence of $1 \mu \mathrm{M}$ tetrodotoxin (TTX, Alomone Labs, Jerusalem, Israel), $50 \mu \mathrm{M}$ APV (Tocris Bioscience, Ellisville, MO), $50 \mu \mathrm{M}$ picrotoxin (Sigma-Aldrich, St Louis, MO), and $25 \mu \mathrm{M}$ CGP-35348 (Tocris) in ACSF. Signals were amplified with an Axoclamp2A amplifier coupled to a 4-pole Bessel filter/amplifier $(1 \mathrm{kHz}, \times 100$, Cornerstone) and digitized online $(20 \mathrm{kHz}$, Digidata 1200A, Axon), then stored on computer disk for later analysis.

Non-stationary noise analysis. AMPAR single-channel conductance was estimated by offline NSNA of mEPSCs using MiniAnalysis 6.0 (Synaptosoft, Decatur, GA). Miniature events were detected over $10 \mathrm{~min}$ (1 day) or $20 \mathrm{~min}$ (2 days) recording. As reported earlier, only fast events (10-90\% rise time $\leqslant 3 \mathrm{~ms}$ ) with an amplitude of $\geqslant 8 \mathrm{pA}$ were used (Shen et al, 2009). All selected events were baseline-adjusted, peak-scaled, superimposed, and compared with the peak-scaled mean. The variance of amplitudes during the decay phase was plotted against mean amplitude of mEPSC currents and fitted with the equation: $\sigma^{2}=i^{*} I-I^{2} / N$ where $\sigma^{2}$ is the variance of the mEPSC, $i$ indicates the unitary current, $I$ represents the mean of whole-cell current, and $N$ is the total number of channels. The single-channel conductance was calculated by Ohm's law: $\gamma=i /\left(V_{\mathrm{H}}-V_{\text {rev }}\right)$, where $V_{\mathrm{H}}$ is $-80 \mathrm{mV}$ and $V_{\text {rev }}$ of AMPAR currents was $0 \mathrm{mV}$.

I/O relationship. Evoked AMPAR-mediated EPSCs (eEPSCs, $V_{\mathrm{H}}=-80 \mathrm{mV}$ ) were induced in the absence of TTX, with a bipolar-stimulating electrode placed in the Schaffer-collateral pathway. I/O curves were constructed by varying stimulus intensity (V) and measuring peak ESPC current amplitude (pA) from EPSC threshold to spike threshold. The slope of both mean and individual I/O curves was calculated to estimate synaptic efficacy of AMPAR responses.

Paired-pulse facilitation. Stimulus intensity was then adjusted to induce half-maximal responses, and paired pulses were delivered at intervals from 25 to $200 \mathrm{~ms}$ in $25 \mathrm{~ms}$ increments. Paired pulses were elicited at a frequency of $0.16 \mathrm{~Hz}$. Peak amplitude for individual, paired-pulse responses was measured as the difference between the baseline before the stimulus artifact and the peak eEPSC. $\mathrm{PPF}$ was calculated as $\left(\mathrm{EPSC}_{2}-\mathrm{EPSC}_{1}\right) / \mathrm{EPSC}_{1} \times 100$.

Spermine analog inhibition. Three AMPAR subpopulations are primarily expressed in rat hippocampus, GluA1/2, and GluA2/3 heteromers, and to a lesser extent GluA1 homomers (Moga et al, 2003; Wenthold et al, 1996). Heteromeric GluA2-containing AMPARs exhibit low permeability for divalent cations such as $\mathrm{Ca}^{2+}$, whereas GluA2lacking receptors have high divalent cation permeability (Hollmann et al, 1991). Furthermore, GluA2-containing and GluA2-lacking AMPARs also differ in their pharmacological properties, in particular blockade by extracellularly applied polyamine-containing spider and wasp toxins (Washburn and Dingledine, 1996). To evaluate whether GluA2-lacking receptors were present at CA1 neurons synapses during FZP withdrawal, $100 \mu \mathrm{M}$ 1-naphthyl acetyl spermine (NAS, Sigma-Aldrich) was added to the perfusate in the presence of $10 \mu \mathrm{M}$ APV during AMPAR-mediated $\left(V_{\mathrm{H}}=-80 \mathrm{mV}\right)$ mEPSC recordings before $(10 \mathrm{~min})$ and after $(7 \mathrm{~min})$ NAS application. Mean mEPSC amplitude was measured before and after NAS application and the percentage decrease after NAS was calculated.

Furthermore, GluA2-containing AMPARs show linear current-voltage $(I-V)$ relationships or outward rectification, whereas GluA2-lacking AMPAR subunits are prone to spermine blockade and show inward rectification at positive holding potentials (Washburn and Dingledine, 1996). Analogous to recordings in 2-day FZP-withdrawn rats (Song et al, 2007), rectification studies were carried out in hippocampal slices from 1-day FZP-withdrawn rats with $100 \mu \mathrm{M}$ spermine in the micropipette. The rectification index was defined as peak current amplitude at a holding potential of $+40 \mathrm{mV}$ divided by that at $-60 \mathrm{mV}$.

\section{Immunoblot Analyses of CA1 Minislices}

Subcellular fractionation. For immunoblotting, hippocampi were isolated from three matched pairs of control and FZP-withdrawn rats and pooled (21 rats/group; $n=7$ wells/ group; 2 -day GluA1 33 rats/group, $n=11$ wells/group; GluA3 (GluR3) and CaMKII $\beta 12$ rats/group; $n=4$ wells/ group). The CA1 region was microdissected from the whole hippocampus, then homogenized and centrifuged to obtain a cytosolic fraction (S2), crude membrane pellet (P2), and a PSD-enriched subfraction as earlier described (Song et al, 2007). All procedures were conducted at $0-4{ }^{\circ} \mathrm{C}$.

Immunoblotting. Protein $(15 \mu \mathrm{g} /$ well $)$ was separated by $10 \%$ SDS-PAGE and wet transferred to nitrocellulose. Primary antibodies anti-GluA1 (1:2000, Millipore, Billerica, MA), anti-phopho-Ser ${ }^{831}$-GluA1 (1:1000, Millipore), antiGluA2 (1:2000, Millipore), anti-GluA3 (1:100, Millipore), anti-CaMKII $\alpha$ (1:5000, Millipore), anti-phospho-Thr ${ }^{286}$ CaMKII ( $1: 1000$, Promega Corporation, Madison, WI), anti-CaMKII $\beta$ ( $1: 1000$, Abcam, Cambridge, MA), anti-actin (1:50000, Millipore), or anti-GAPDH (1:20000, Abcam) were incubated with membranes overnight at $4{ }^{\circ} \mathrm{C}$. Antibody signals were detected with anti-rabbit or anti-mouse horseradish peroxidase-conjugated secondary antibodies (1:10000, Jackson ImmunoResearch, West Grove, PA), followed by enhanced chemiluminescence (Denville Scientific, Metuchen, NJ). Images of immunoblots were scanned and immunoreactivity quantified with ImageJ software, v. 1.36b (National Institutes of Health, Bethesda, MD). GluA or CaMKII subunit signals were normalized to the corresponding GAPDH or actin signal.

\section{RESULTS}

\section{Postsynaptic Mechanisms of AMPAR Potentiation During Benzodiazepine Withdrawal}

As earlier reported (Van Sickle and Tietz, 2002; Xiang and Tietz, 2007), the amplitude of AMPAR-mediated mEPSCs was significantly increased in CA1 neurons from 2-day 

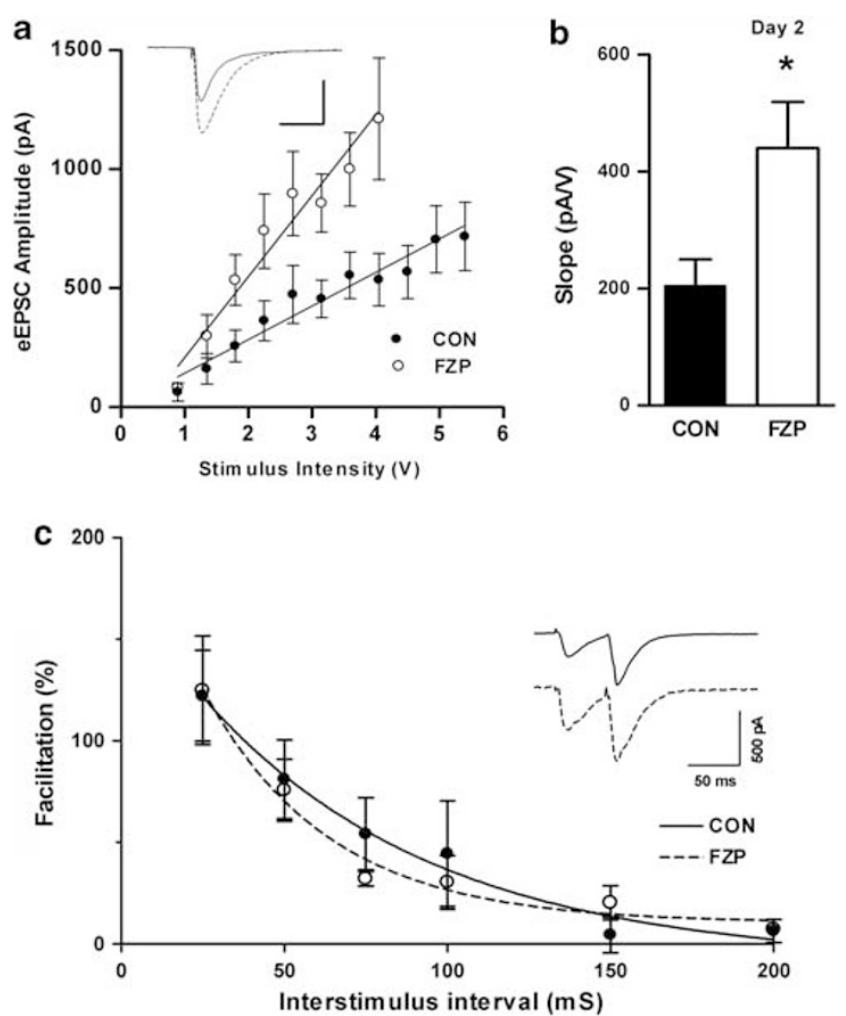

Figure I The slope of the input-output $(1 / O)$ relationship, but not paired-pulse facilitation (PPF) was increased in CAI neurons from 2-day FZP-withdrawn rats. (a) Evoked EPSC $\left(V_{H}=-80 \mathrm{mV}\right.$ ) amplitude ( $\left.p A\right)$ was plotted as a function of stimulus intensity $(\mathrm{V})$. Linear regression of pooled $1 / O$ relationships showed an $\sim 2$.5-fold increase in the stimulus response relationship in CAI neurons from FZP-withdrawn (open circles, $n=9$ ) compared with control (closed circles, $n=7$ ) rats. Inset: Representative traces of eEPSCs elicited at $3.6 \mathrm{~V}$ (solid line: CON; broken line: FZP). Scale as in inset in (c). (b) The mean slope of the $1 / O$ curve derived from the fits of individual $1 / O$ curves generated in neurons from FZP-withdrawn rats $(440.0 \pm 79.4 \mathrm{pAN}, n=9)$ was also significantly greater than that from control rats $(205.3 \pm 44.5 p A N, n=7)$. The data are consistent with an increase in CAI neuron AMPAR synaptic efficacy in FZP-withdrawn rats. Asterisks denote $p<0.05$. (c) PPF of AMPAR was unchanged in 2-day FZP-withdrawn rats. The amplitude of AMPAR-mediated eEPSCs $\left(V_{H}=-80 \mathrm{mV}\right)$ after half-maximal stimulation of the Schaffer-collateral pathway. Paired-pulse stimulation was applied and the response was recorded at the interstimulus intervals ranging from 25 to $200 \mathrm{~ms}$ in $25 \mathrm{~ms}$ increments. Inset: Representative paired EPSC traces recorded in CAI neurons from control and FZP-withdrawn rats. Paired EPSC amplitudes were calculated as the difference between baseline before the stimulus artifact and EPSC peak. PPF was calculated as (EPSC2-EPSCI)/ EPSCI $\times 100$. Percent facilitation was plotted (CON, closed circles, $n=5$; FZP: closed circles, $n=5$ ) and fit with a single-exponential decay function. No significant differences between groups were found at any interstimulus interval suggesting that glutamate release onto CAI neurons was unaltered.

FZP-withdrawn rats without effect on mEPSC frequency, rise-time, decay kinetics, or resting membrane potential (RMP). I/O experiments confirmed an increased efficacy of synaptic transmission in CA1 neurons from FZP-withdrawn rats. As shown in Figure 1a, an I/O curve generated by plotting mean evoked EPSC amplitude (pA) vs mean stimulus intensity (V), showed an $\sim 2.5$-fold increase in slope. A similar result (Figure 1b) was obtained when comparing the mean slope of fits of individual I/O curves (CON, $205.3 \pm 44.5 \mathrm{pA} / \mathrm{V}$ vs FZP, $440.0 \pm 79.4 \mathrm{pA} / \mathrm{V}$, $p<0.05)$. The potentiation of AMPAR-mediated synaptic transmission reflected in the enhanced slope of the FZP-withdrawn I/O curve paralleled an increase in population spike amplitude (Shen et al, 2009) and in overall CA1 neuron hyperexcitability (Van Sickle et al, 2004) in FZP-withdrawn neurons.

Although mEPSC frequency, which reflects random release of glutamate from presynaptic neurons was not different between groups (Van Sickle and Tietz, 2002; Van Sickle et al, 2004; Shen et al, 2009), PPF studies were carried out to verify that evoked glutamate release was also not affected during drug withdrawal. Maximal facilitation was observed at the shortest interstimulus interval tested $(25 \mathrm{~ms})$ and decayed exponentially with increasing interstimulus intervals $(25-200 \mathrm{~ms})$. Consistent with the enhancement of synaptic efficacy in FZP-withdrawn neurons, FZP half-maximal responses tended to be greater than in control rats, yet there were no significant differences in the half-maximal response $(\mathrm{CON}, 171.5 \pm 41.6 \mathrm{pA}$ vs FZP, $314.3 \pm 69.6 \mathrm{pA}, n=5$ /group, $p=0.12)$ or stimulus intensity $(\mathrm{CON}, 0.34 \pm 0.09 \mathrm{~V}$ vs FZP, $0.23 \pm 0.04 \mathrm{~V}, n=5$ /group, $p=0.28$, Student's $t$-test) used to elicit PPF. There were no significant differences $(p=0.23-0.94)$ among PPF responses between experimental groups at any interstimulus interval (Figure 1c inset: representative traces) reflected in the overlap of the single-exponential decay fits (Figure 1c). Taken together, the lack of change in mEPSC frequency and PPF suggests that glutamate release was unchanged between experimental groups excluding presynaptic involvement in benzodiazepine withdrawal-induced AMPAR potentiation.

In models of activity-dependent plasticity, such as longterm potentiation (LTP), CaMKII is primarily activated by $\mathrm{Ca}^{2+}$ influx through $N$-methyl-D-aspartate receptors (NMDARs) (Collingridge et al, 2004) and potentiates synaptic efficacy by inducing synaptic insertion of AMPARs, as well as increasing AMPAR single-channel conductance through CaMKII-mediated Ser ${ }^{831}$ GluA1 subunit phosphorylation (Lisman et al, 2002). AMPAR conductance in CA1 neurons from 2-day FZP-withdrawn rats nearly doubled from 8.5 to $14.7 \mathrm{pS}$ (Shen et al, 2009), an observation that resembled CaMKII-mediated phosphorylation of GluA1 subunits in LTP (Barria et al, 1997b) and modulation of AMPAR conductance in recombinant GluA1 homomeric AMPARs (Derkach et al, 1999). As mEPSC amplitude was significantly increased in 1-day FZP-withdrawn rats (Van Sickle and Tietz, 2002), NSNA was also used to estimate single-channel conductance at this withdrawal time point. Unlike in recordings from 2-day withdrawn rats, NSNA analysis of mEPSCs in CA1 neurons from control and 1-day FZP-withdrawn rats confirmed an enhanced AMPAR amplitude (Figure 2a; CON, 9.4 $\pm 0.2 \mathrm{pA}$, $n=6$ vs FZP, $10.3 \pm 0.3 \mathrm{pA}, n=7, p=0.04)$, without a change in conductance level (Figure $3 \mathrm{~b}, \mathrm{CON}, 11.0 \pm 0.6 \mathrm{pS}$, $n=6$ vs FZP, $11.8 \pm 1.2 \mathrm{pS}, n=7)$.

The enhanced mEPSC amplitude and estimated singlechannel conductance in CA1 neurons were consistent with earlier findings from both juvenile and adult 2-day FZPwithdrawn rats (Van Sickle and Tietz, 2002, Van Sickle et al, 2004; Shen et al, 2009) and with a CaMKII-mediated mechanism regulating AMPAR potentiation during benzodiazepine withdrawal. Indeed, both effects were eliminated 

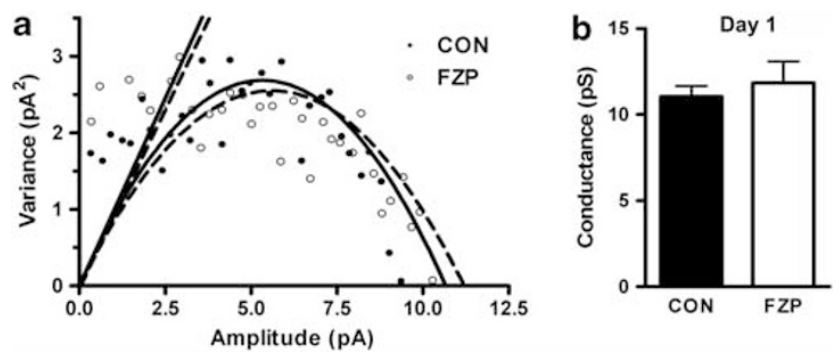

Figure 2 AMPAR-mediated mEPSC amplitude, but not conductance was increased in I-day FZP-withdrawn rats. mEPSC amplitude was increased in I-day FZP-withdrawn rats without an effect on mEPSC frequency, rise time or decay kinetics, or RMP. (a) Representative plot of the results of non-stationary noise analysis (NSNA) of mEPSCs showed an increase in current amplitude, but no change in slope conductance in an FZP-withdrawn (open circles/dotted line) vs a CON (close circles/solid line) neuron. (b) Mean mEPSC conductance in CAI neurons from CON (closed bars, $n=6$ ) and I-day FZP-withdrawn (open bars, $n=7$ ) rats indicated no significant difference in AMPAR conductance between experimental groups at this time point.

by preincubation $(2 \mathrm{~h})$ of hippocampal slices with the CaMKII inhibitor, KN-93 (Shen et al, 2009). However, as bath-applied KN93 and KN92 can have presynaptic actions and also have effects on L-type voltage-gated $\mathrm{Ca}^{2+}$ channels (Gao et al, 2006), the postsynaptic effects of CaMKII on AMPAR potentiation were further evaluated by inclusion of the CaMKII inhibitors, AIP or ACM, in the micropipette. sAIP, at the same concentration, was used as a negative control. The effects of the more selective inhibitor, CaMKIINtide (Sanhueza et al, 2007), were also evaluated in several control and 2-day FZP-withdrawn neurons. A comparison between neurons recorded in ACSF without sAIP in the micropipette ( $n=9$ cells/experimental group; Shen et al, 2009) and those in this study (Table 1) did not reveal any significant differences among control group values. Inclusion of the active peptide, AIP, blocked AMPAR potentiation (Figure 3; Table 1). That is, both the increased AMPAR-mediated mEPSC amplitude and AMPAR single-channel conductance in neurons from 2-day FZP-withdrawn rats returned to control levels. As shown in Figure 3 and Table 1, intracellular application of sAIP had no significant effect on mEPSC amplitude (Figure 3a) or single-channel conductance (Figure $3 \mathrm{c}$ ) in FZP-withdrawn $v s$ control neurons in which mEPSCs remained significantly increased. The estimated singlechannel conductance derived from a representative set of recordings from each experimental group is shown in Figure 3b. The effect of the less-potent CaMKII inhibitor, ACM, did not reach statistical significance (Table 1). As with AIP, intracellular inclusion of CaMKIINtide prevented both the increase in peak amplitude $(\mathrm{CON}, 9.3 \pm 1.1 \mathrm{pA}$, $n=4 ; \mathrm{FZP}, 10.1 \pm 2.4 \mathrm{pA}, n=3, p=0.58)$ and estimated conductance $(\mathrm{CON}, 8.9 \pm 0.5 \mathrm{pS}, n=4$; FZP, $9.6 \pm 0.2 \mathrm{pS}$, $n=3, p=0.76)$ without an effect on RMP, rise-time, or $\tau$ of decay.

\section{GluA2-Lacking Receptors Mediate AMPAR Potentiation}

As the number of AMPAR-binding sites and of GluA1- but not GluA2-containing AMPARs was increased at CA1 neuron synapses in FZP-withdrawn rats (Das et al, 2008;
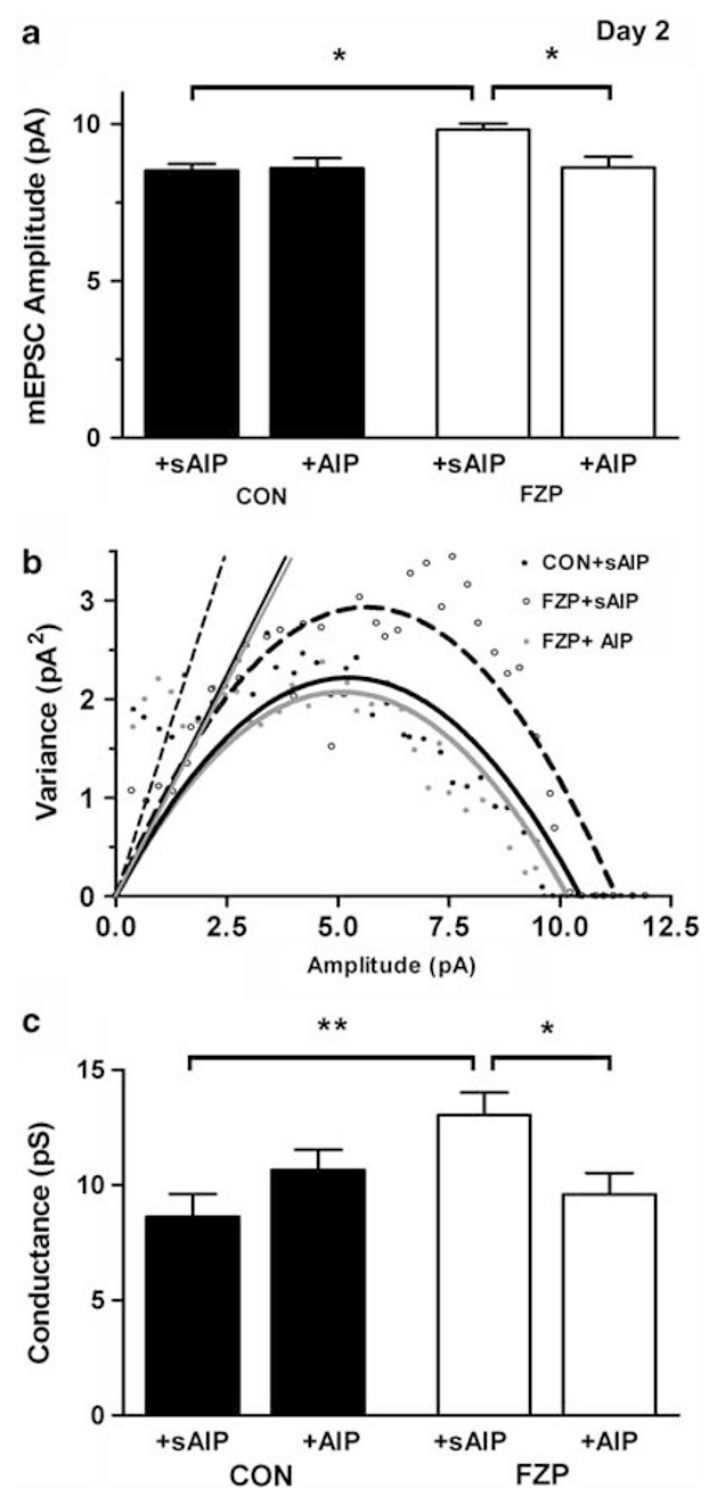

Figure 3 Both AMPAR amplitude and single-channel conductance was reversed by intracellular inclusion of a CaMKII inhibitor. As recorded in ACSF alone (Shen et al, 2009) and as shown in Table I, mEPSC (a) amplitude and (c) conductance were significantly increased in 2-day FZPwithdrawn rats in the negative control condition, with scrambled autocamtide inhibitory peptide (sAIP) in the whole-cell micropipette. (b) Representative plot of the results of NSNA of mEPSCs showing an increased current amplitude and slope conductance in an FZP-withdrawn neuron with sAIP (open circles/dotted line) vs a CON neuron with sAIP (close circles/black solid line). Intracellular inclusion of the active CaMKII inhibitor, + AIP reversed both the increased AMPAR-mediated mEPSC (a) amplitude and (c) elevated single-channel conductance to control levels ( + sAIP) as illustrated in (b) (gray circles/gray solid line). CaMKIINtide inclusion in a few neurons had a similar effect, suggesting that AMPAR potentiation is mediated by CaMKIl $\alpha$ activation. $* p<0.05$; $* * * 0.0$ I.

Song et al, 2007; Van Sickle and Tietz, 2002), an enhancement in AMPAR current amplitude was proposed to be due to an increase in the numbers of GluA2-lacking AMPAR numbers. Inward rectification in the presence of spermine or its analogs was, therefore, used as an electrophysiological tag for the detection of $\mathrm{Ca}^{2+}$-permeable, GluA2-lacking AMPAR (Derkach et al, 1999). mEPSCs recorded from CA1 neurons in hippocampal slices from FZP-withdrawn rats showed 
Table I mEPSC characteristics after postsynaptic application of CaMKII inhibitors

\begin{tabular}{|c|c|c|c|c|c|c|}
\hline Group (\# cells) & RMP (mV) & Frequency $(\mathrm{Hz})$ & Rise time (ms) & Amplitude (pA) & Decay $\tau(\mathrm{ms})$ & Conductance $(\mathrm{pS})$ \\
\hline \multicolumn{7}{|l|}{$\overline{C O N}$} \\
\hline$+s \mathrm{AIP}(n=7)$ & $-68.3 \pm 1.0$ & $0.23 \pm 0.03$ & $3.6 \pm 0.3$ & $-8.5 \pm 0.2$ & $19.5 \pm 1.6$ & $8.6 \pm 1.0$ \\
\hline$+\operatorname{AIP}(n=6)$ & $-66.0 \pm 1.4$ & $0.40 \pm 0.09$ & $2.9 \pm 0.2$ & $-8.6 \pm 0.3$ & $18.2 \pm 1.1$ & $10.7 \pm 0.9$ \\
\hline$+\operatorname{ACM}(n=7)$ & $-65.6 \pm 1.9$ & $0.30 \pm 0.09$ & $3.0 \pm 0.2$ & $-8.7 \pm 0.2$ & $17.8 \pm 0.9$ & $10.4 \pm 0.4$ \\
\hline$+\operatorname{AIP}(n=8)$ & $-67.6 \pm 1.9$ & $0.37 \pm 0.09$ & $3.2 \pm 0.2$ & $-8.6 \pm 0.4^{\dagger}$ & $19.5 \pm 1.5$ & $9.6 \pm 0.9$ \\
\hline$+\operatorname{ACM}(n=9)$ & $-67.1 \pm 2.3$ & $0.27 \pm 0.03$ & $3.2 \pm 0.1$ & $-9.3 \pm 0.3$ & $17.4 \pm 1.4$ & $10.8 \pm 0.6$ \\
\hline
\end{tabular}

Values are listed as means \pm SEM. * $p<0.05\left(\mathrm{CON}+\right.$ sAIP vs FZP+sAIP); $* * * 0.01 ;{ }^{\dagger} p<0.05(\mathrm{FZP}+$ sAIP vs FZP+AIP).

a decreased $+40 /-60$ rectification index with $100 \mu \mathrm{M}$ spermine in the micropipette (Song et al, 2007). A similar effect on rectification index was observed in neurons evaluated from 1-day FZP-withdrawn rats (FZP, $0.56 \pm 0.05, n=8$; CON, $0.81 \pm 0.06, n=8, p<0.01$ ). Furthermore as illustrated by its effect on representative average mEPSCs (Figure 4a and d), extracellular application of NAS, another selective inhibitor of AMPAR currents mediated by GluA2-lacking receptors, had a significantly greater effect to inhibit AMPAR-mediated mEPSC amplitude in CA1 neurons from 1- and 2-day FZP-withdrawn vs control rats (Figure 4b and e). Removing the synaptic current component mediated by $\mathrm{Ca}^{2+}$-permeable AMPARs with NAS also abolished the potentiation of mEPSC amplitude in neurons from FZPwithdrawn rats (Figure $4 \mathrm{c}$ and $\mathrm{f}$ ) (1 day: FZP, $10.3 \pm 0.3 \mathrm{pA} v \mathrm{~s}$ FZP + NAS, $8.3 \pm 0.4 \mathrm{pA}, n=7, p=0.002 ; 2$ days: FZP, $10.6 \pm 0.3 \mathrm{pA} v s \mathrm{FZP}+\mathrm{NAS}, 8.4 \pm 0.4 \mathrm{pA}, n=12, p<0.0001)$ The effect might be smaller in control neurons as GluA1 homomers make up $<10 \%$ of AMPARs ( 1 day: CON, $9.4 \pm 0.2 \mathrm{pA} v s \mathrm{CON}+\mathrm{NAS}, 8.5 \pm 0.2 \mathrm{pA}, n=6, p=0.01 ; 2$ days: $\mathrm{CON}, 9.0 \pm 0.3 \mathrm{pA}$ vs $\mathrm{CON}+\mathrm{NAS}, 8.1 \pm 0.4 \mathrm{pA}, n=7$, $p=0.10)$. This finding lent further support to the hypothesis that AMPAR potentiation during drug withdrawal was mediated by incorporation of GluA2-lacking AMPAR into CA1 neuron synapses.

\section{Expression Pattern of GluA and CaMKII Subunits in PSD-Enriched Subcellular Fractions}

Electrophysiological findings in 1- and 2-day FZP-withdrawn rats (Figures 2 and 3; Van Sickle et al, 2004; Shen et al, 2009) suggested that synaptic incorporation of GluA1containing AMPAR may mediate the increase in mEPSC amplitude and that subsequent CaMKII-mediated phosphorylation of Ser ${ }^{831}$ GluA1 may mediate enhanced AMPAR conductance. Therefore, total and phospho(p) Ser ${ }^{831}$ GluA1 subunit levels were examined by immunoblot analysis of proteins in PSD-enriched subcellular fractions of CA1 minislices from 1- and 2-day FZP-withdrawn rats. GluA1 and $\mathrm{pSer}^{831} \mathrm{GluA} 1$ expression levels in the cytosolic (S2) and crude membrane (P2) subfractions (data not shown) were unchanged after 2-day withdrawal. However, total GluA1 expression levels in the PSD-enriched subfraction were
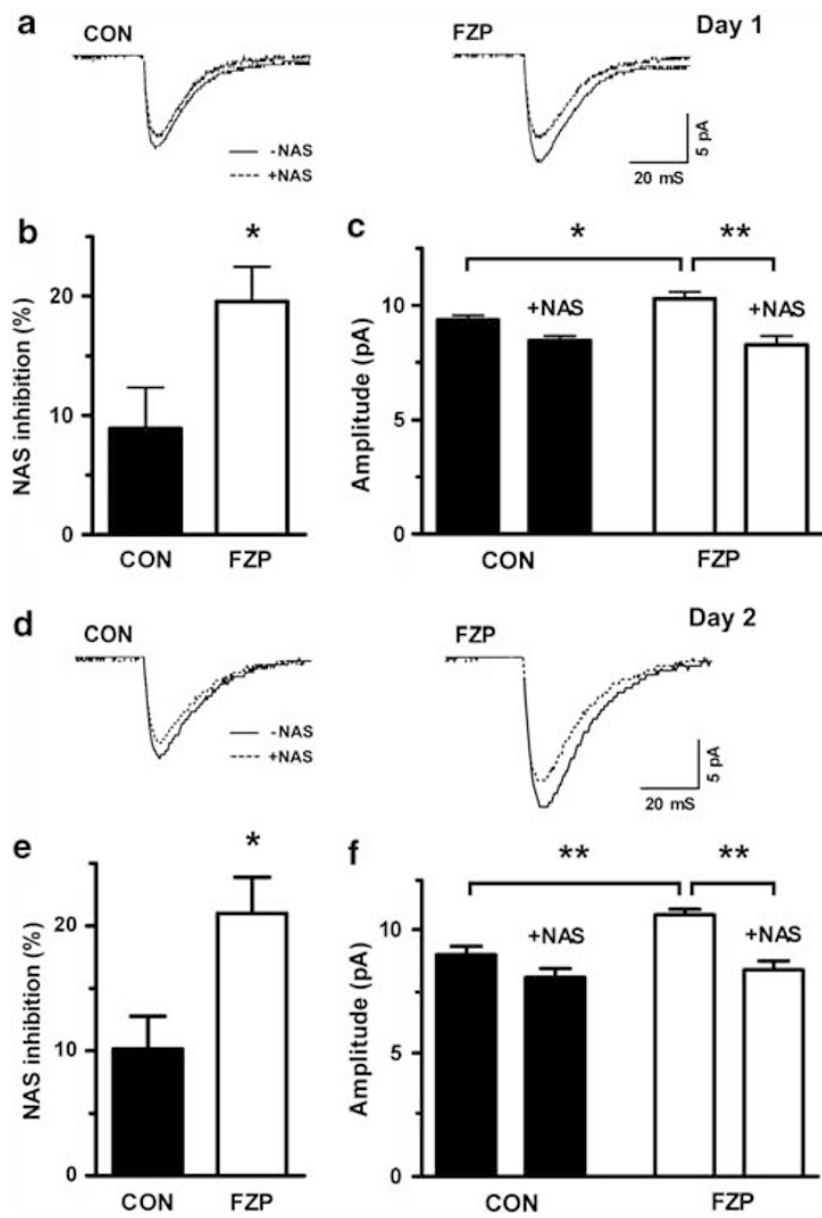

Figure 4 Greater NAS inhibition in neurons from I- and 2-day FZPwithdrawn rats. Representative AMPAR-mediated mEPSCs (a, I day; d, 2 days) recorded before (solid line) and after (dotted line) external application of the potent spermine analog, NAS (100 $\mu \mathrm{M})$. The percent NAS inhibition of mEPSC current amplitude was increased (b, I day; e, 2 days) in CAI neurons from FZP-withdrawn rats $(p<0.05)$. Bath application of NAS abolished the increased AMPAR-mediated mEPSC amplitude in FZP-withdrawn neurons after (c) I day $(n=7)$ and ( $f) 2$ days $(n=12)$ and was without effect in control neurons ( 1 day, $n=6 ; 2$ days, $n=7$ ), supporting the hypothesis that AMPAR current potentiation is mediated by synaptic incorporation of GluA2-lacking AMPARs. Asterisks denote $p \leqslant 0.05$ or ${ }^{*} * * 0.01$. 
elevated in both 1- and 2-day FZP-withdrawn subfractions (Figure 5a and b), as reported earlier after 2 days (Song et al, 2007). As in 2-day FZP-withdrawn tissues (Das et al, 2008; Song et al, 2007), GluA2 subunit protein levels were also unchanged in 1-day FZP-withdrawn subfractions (Figure 5b). As shown in the lower panels in Figure 5b, pSer ${ }^{831}$ GluA1 subunit levels were elevated in PSD-enriched subfractions in 2-day, but not 1-day FZP-withdrawn

a
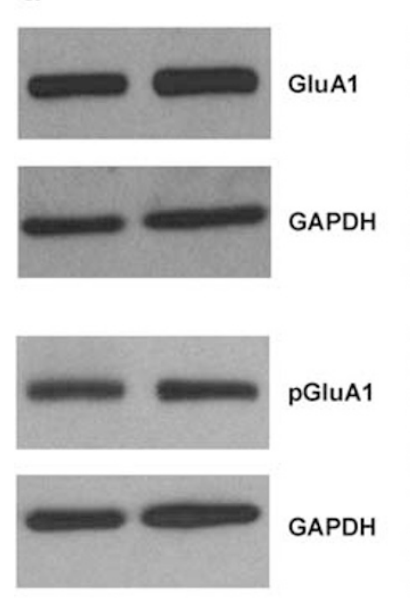

pGluA1

GAPDH

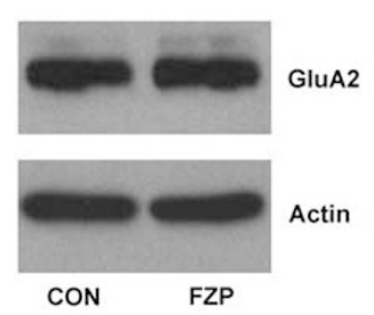

b
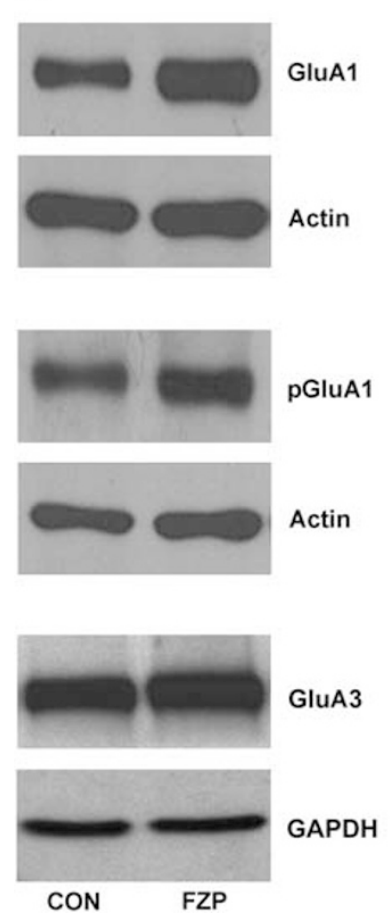

GluA3

GAPDH
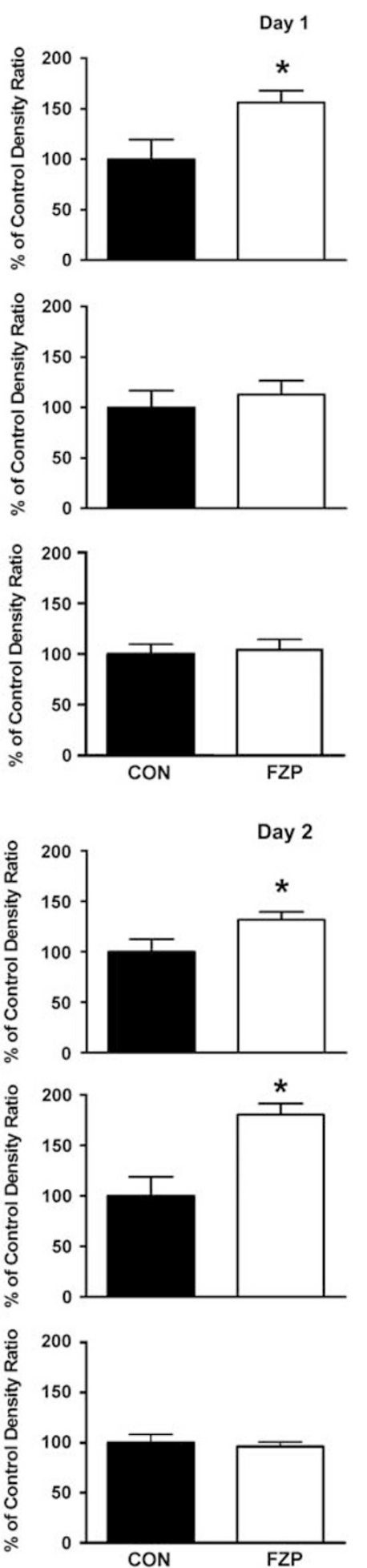

subfractions (Figure 5a), consistent with an increase in AMPAR conductance in neurons from 2-day (Figure 3; Shen et al, 2009) but not 1-day FZP-withdrawn rats (Figure 2).

The increased expression of GluAl subunits in CA1 minislices from 1-day FZP-withdrawn rats provides support for the proposal that GluAl-containing AMPARs were incorporated into CA1 synapses before Ser $^{831}$ phosphorylation by CaMKII resulting in a subsequent functional increase in AMPAR single-channel conductance ( $\mathrm{Oh}$ and Derkach, 2005). Nonetheless, benzodiazepine withdrawal-induced $\mathrm{Ca}^{2+}$ permeable AMPAR complexes could include GluA1 and GluA3 homomers or additionally GluA1/GluA3 heteromers, a composition that cannot be pharmacologically distinguished by NAS-mediated blockade (Figure 4). Thus, as an initial step to distinguish among these possibilities, GluA3 subunit levels were also assessed in 2-day FZP-withdrawn minislices. Figure $6 \mathrm{~b}$ shows that GluA3 subunit levels were unchanged in the PSD-enriched subfraction from 2-day FZP-withdrawn minislices. These data suggest that GluA3-containing AMPAR did not contribute to the shift in inward rectification index (Song et al, 2007) or to enhanced $\mathrm{Ca}^{2+}$-permeable AMPAR currents (Figure 4), thus did not have a function to enhance excitatory synaptic transmission in FZP-withdrawn neurons. Taken together, these data provide further support for the interpretation that AMPAR potentiation is related to synaptic incorporation and phosphorylation of GluA1 homomers.

As $\operatorname{Ser}^{831}$ GluA1 has been identified as a substrate of CaMKII (Barria et al, 1997a; Mammen et al, 1997) and can be phosphorylated by the constitutively active form, phospho(p)Thr ${ }^{286}$-CaMKII, the expression levels of totaland $\mathrm{pThr}^{286}$-CaMKII were also examined in all subfractions derived from 1- and 2-day FZP-withdrawn minislices. Total CaMKII protein levels were significantly and ubiquitously increased in all three subfractions (S2, P2: data not shown) including PSD-enriched subfractions from 2-day but not 1-day FZP-withdrawn CA1 minislices (Figure $6 \mathrm{a}$ and b), providing a possible mechanism for $\operatorname{Ser}^{831}$ phosphorylation of AMPAR GluA1 subunits at the latter withdrawal time point. But unlike changes in $\mathrm{pThr}^{286}$-CaMKII associated with LTP induction (Lisman et al, 2002; Bayer et al, 2006), expression levels of the constitutively active form of CaMKII were unchanged at both time points after drug withdrawal (Figure 6a and $\mathrm{b}$ ). As a small fraction of CaMKII $\beta$ can dock the more prevalent, CaMKII $\alpha$ to the actin cytoskeleton (Shen et al, 1998), CaMKII $\beta$ levels were also compared in these PSD-enriched subfractions. There were no significant

Figure 5 GluA subunit levels in CAI PSD-enriched subcellular fractions as a function of time after drug withdrawal. PSD-enriched subfractions were collected by ultracentrifugation of TritonX-100-resistant membranes pooled from three hippocampal CAI minislices as described in Materials and methods. Representative immunoblots of total GluAI and pSer ${ }^{831}$ GluAI with their respective loading controls are shown in PSD-enriched subfractions from (a) I-day and (b) 2-day FZP-withdrawn rats in the leftmost panels. Histograms of integrated signal density as a percent of paired control density ( $n=4-1$ I lanes/group) are shown to the right. Only total-GluAI expression levels were significantly enhanced in I-day FZPwithdrawn rats, whereas both total and $\mathrm{PSer}{ }^{831} \mathrm{GluAl}$ levels were increased in 2-day FZP-withdrawn rats. There were no changes in GluA2 levels in I-day (or 2-day; Das et al, 2008; Song et al, 2007) FZP-withdrawn rats. There were also no changes in GluA3 expression levels in the PSDenriched fraction from 2-day FZP-withdrawn rats. Asterisks denote $p<0.05$. 


\section{a}

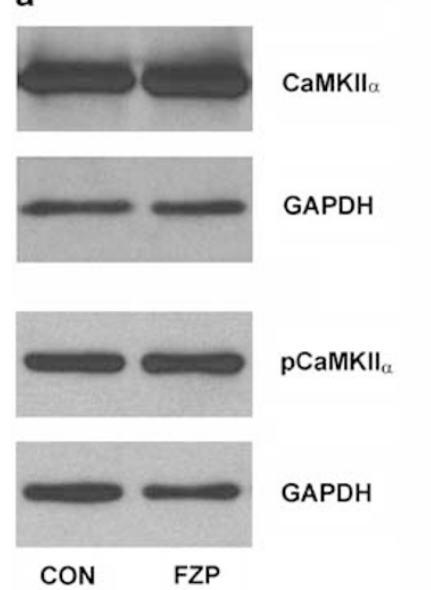

b

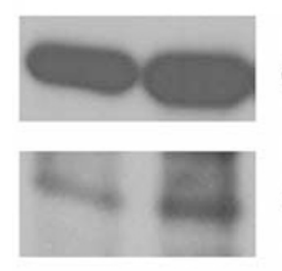

GAPDH

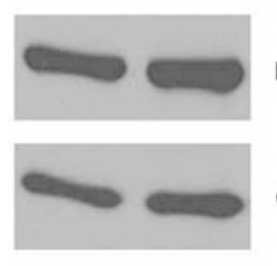

pCaMKII

GAPDH

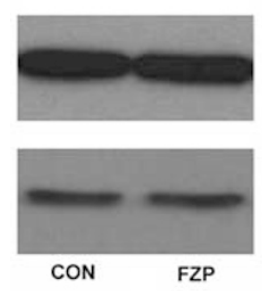

$\mathrm{CaMKII}_{\beta}$

GAPDH
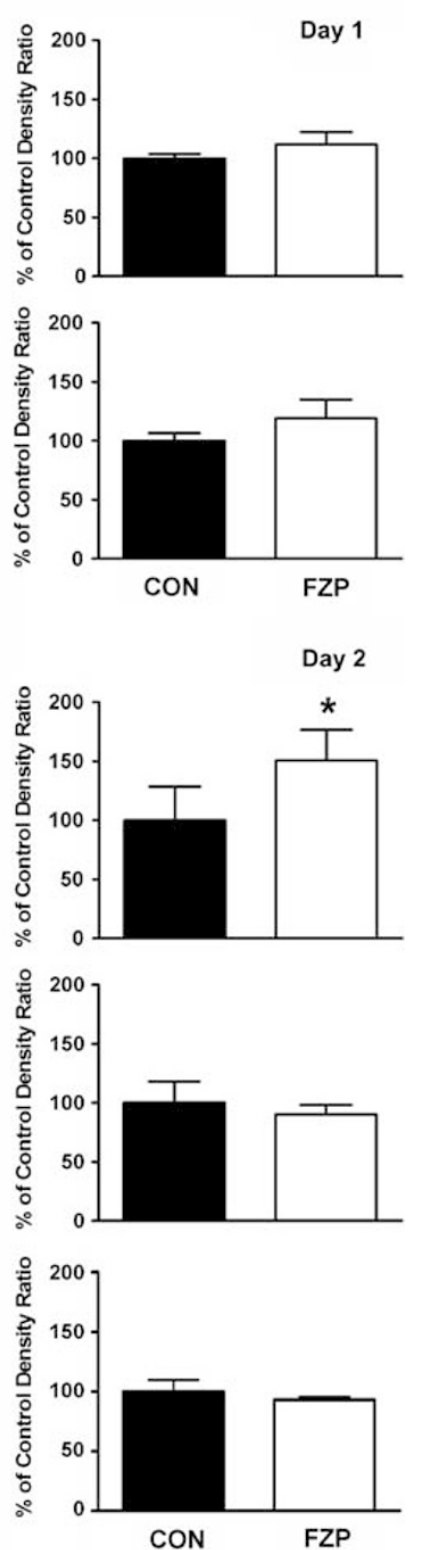

Figure 6 CaMKII subunit levels in CAI PSD-enriched subcellular fractions as a function of time after drug withdrawal. Representative immunoblots of total CaMKIl $\alpha$, pThr ${ }^{286}$-CaMKII $\alpha$, and CaMKII $\beta$ protein with their respective GAPDH loading controls are shown in PSD-enriched subfractions of CAI minislices from (a) I-day and (b) 2-day FZP-withdrawn rats in the leftmost panels. Histograms of integrated signal density as a percent of the paired control density ( $n=4-7$ lanes/group) are shown to the right. Total-CaMKIl $\alpha$ expression levels were significantly increased in 2day FZP-withdrawn rats. No significant changes in $\mathrm{PThr}^{286}-\mathrm{CaMKIl} \alpha$ or CaMKII $\beta$ expression levels were found. Asterisks denote $p<0.05$.

differences in CaMKII $\beta$ expression in the PSD-enriched subfraction derived from 2-day FZP-withdrawn minislices (Figure 6b).

\section{DISCUSSION}

\section{Enhanced AMPAR Postsynaptic Efficacy}

A significant link was earlier established between the increased efficacy of hippocampal CA1 pyramidal neuron
AMPAR-mediated glutamatergic synaptic transmission and withdrawal-induced anxiety-like behavior (Van Sickle et al, 2004; Xiang and Tietz, 2007), consistent with the findings in other benzodiazepine-withdrawal models (Allison and Pratt, 2003; Izzo et al, 2001) and other animal models of anxiety (Shen et al, 2007). The enhancement of macroscopic glutamate currents and increased AMPAR-mediated mEPSC amplitude in the absence of a change in glutamate affinity or current desensitization was attributable to increased GluA1- but not GluA2-containing AMPARs at CA1 neuron synapses (Das et al, 2008; Song et al, 2007). Along with earlier findings in hippocampal slices (Van Sickle and Tietz, 2002; Van Sickle et al, 2004), the $\sim 2.5$-fold increased slope of the I/O relationship confirmed that AMPAR-mediated synaptic transmission was potentiated in 2-day FZP-withdrawn rats (Figure 1a and b). A similar effect was noted in lateral amygdala slices of fear-conditioned rats (McKernan and Shinnick-Gallagher, 1997). However, unlike in the latter model of emotional learning, presynaptic facilitation of glutamate release was not observed (Figure 1c) and mEPSC frequency was unaltered in FZP-withdrawn rats (Shen et al, 2009; Van Sickle and Tietz, 2002; Van Sickle et al, 2004). In common with current views of mechanisms underlying LTP (Nicoll, 2003), a presynaptic mechanism is not likely central to drug-induced glutamatergic plasticity.

Though earlier experiments showed that bath application of hippocampal slices with the CaMKII inhibitor, KN-93, could prevent AMPAR potentiation during 2-day FZP withdrawal (Shen et al, 2009), a presynaptic mechanism could not be excluded as CaMKII can also modulate neurotransmitter vesicle release (Llinas et al, 1985; Margrie et al, 1998). To rule out presynaptic effects of CaMKII inhibition, various CaMKII inhibitors were included in the micropipette. Intracellular inclusion of AIP, but not the scrambled peptide, as well as CaMKIINtide had a similar effect as the less selective bath-applied inhibitor to prevent potentiation of AMPAR synaptic currents and conductance (Shen et al, 2009). These findings provide strong evidence that postsynaptic CaMKII activation is involved in CA1 neuron hyperexcitability. As with LTP, enhancing CaMKII $\alpha$ activity can lead to synaptic delivery of GluA1-containing AMPARs, an increase in mEPSC quantal size and enhanced AMPAR conductance in hippocampal neurons and heterologous systems (Poncer et al, 2002; Oh and Derkach, 2005). Accordingly, an increase in trafficking and subsequent CaMKII-mediated phosphorylation of GluA1-containing AMPARs (Barria et al, 1997b; Derkach et al, 1999; Esteban et al, 2003; Hayashi et al, 2000) offered a possible molecular basis for synaptic AMPAR potentiation associated with benzodiazepine withdrawal.

\section{Incorporation of Homomeric GluR1 AMPAR}

GluA1/2 heteromers represent a large portion $(\sim 80 \%)$ of native synaptic CA1 neuron AMPARs and GluA2/3 heteromers comprise a dominant fraction of the remainder ( $\mathrm{Lu}$ et al, 2009; Wenthold et al, 1996). GluA1/3 heteromers are rare in the presence of GluA2 subunits (Moga et al, 2003; Sans et al, 2003; Wenthold et al, 1996). GluA4 (GluR4) subunit expression is largely confined to the first PN week (Zhu et al, 2000). A small proportion ( $\sim 8 \%)$ of native AMPAR complexes were proposed to exist as GluA1 
homomers (Wenthold et al, 1996). The small number of CA1 GluA1 homomers resides intracellularly or on nonpyramidal neurons. The intracellular subpopulation is trafficked to the CA1 synapse immediately on a reduction in GluA2 expression ( $\mathrm{Lu}$ et al, 2009). Q/R site editing, complete (>99\%) at all stages of development (Seeburg, 1996) renders AMPAR containing even a single GluA2 subunit $\mathrm{Ca}^{2+}$ impermeable and insensitive to spermine block, whereas GluA2-lacking AMPARs show inward rectification (Pellegrini-Giampietro, 2003; Washburn and Dingledine, 1996, Swanson et al, 1997). Native CA1 neurons exhibit largely linear to outward rectification in response to AMPA (Lerma et al, 1994; Song et al, 2007). The shift in the rectification index in 1- and 2-day FZP-withdrawn neurons (Song et al, 2007) was supportive evidence for functional incorporation of synaptic $\mathrm{Ca}^{2+}$-permeable GluA1-containing AMPARs (Esteban et al, 2003; Shi et al, 1999), though could not exclude an increase in GluA3 homomers or GluA1/3 heteromers (Moga et al, 2003; Pellegrini-Giampietro, 2003). The lack of change in GluA3 expression (Figure 5b) in 2-day withdrawn CA1 PSD-subfractions added support for the interpretation that GluA1 homomers are incorporated into excitatory synapses. The significant increase in spermine analog (NAS) inhibition of mEPSCs in both 1- and 2-day FZP-withdrawn neurons (Figure 4) also supported an increased proportion of incorporation of GluA2-lacking AMPARs, rather than GluA1/2 heteromers into CA1 synapses at both withdrawal time points.

\section{A Two-Step Process: GluR1 Subunit Incorporation and Phosphorylation}

AMPA receptors in CA1 neurons have multiple conductance states (Benke et al, 1998; Swanson et al, 1997). AMPAR conductance $(\gamma)$ at CA1 synapses was estimated to be $7.7 \mathrm{pS}$, the range (1.5-22.3 pS, PN13-15) related to synaptic variation. Glutamate has concentration-dependent effects to increase AMPAR-channel conductance (Gebhardt and Cull-Candy, 2006), and synaptic concentrations (1 mM) applied to outside-out CA1 dendritic patches revealed a mean conductance of $10.2 \mathrm{pS}$, despite their low-calcium permeability $\left(P_{\mathrm{Ca} 2+/ \mathrm{Cs}+} \sim 0.5\right)$ (Spruston $e$ al, 1995; PN13$28)$. Very low conductance channels ( $\sim 300 \mathrm{fS})$, attributable to fully RNA-edited GluA2-containing receptors in native assemblies (Seeburg, 1996), reduced the weighted mean conductance (Swanson et al, 1997). GluA2-containing receptors expressed in HEK-293 cells had conductances of $\sim 2-3 \mathrm{pS}$ (Oh and Derkach, 2005), whereas 9 and $14 \mathrm{pS}$ conductance states dominated GluA1 homomers, representing $85 \%$ of channel openings. Co-expression of CaMKII, GluA1 Ser ${ }^{831}$ phosphorylation, or mutation of Ser ${ }^{831}$ to Asp, increased the occurrence of far less frequent, higher conductance states (21 and $28 \mathrm{pS}$, Derkach et al, 1999; Oh and Derkach, 2005). Importantly, the latter increased GluA1 conductance was only functionally expressed in the absence of assembled GluA2 subunits (Oh and Derkach, 2005). These findings imply that a subpopulation of primarily $\mathrm{Ca}^{2}$ ${ }^{+}$-impermeable GluA2-containing AMPARs, including extrasynaptic somatic receptors (Lerma et al, 1994; Lu et al, 2009) with lower conductance states, offsets a mixed population of higher conductance state dendritic AMPARs, each making a contribution to the whole-cell weighted mean conductance (Benke et al, 1998; Spruston et al, 1995).

The mean conductance derived from NSNA analysis of mEPSCs in CA1 neurons from control and 2-day FZPwithdrawn rats (Table 1; PN36-42), was comparable with that earlier observed in this model (Shen et al, 2009). As GluA1 but not GluA2 subunit expression was not increased in 1-day FZP-withdrawn rats (Figure 5), and glutamate affinity was unchanged during FZP withdrawal (Song et al, 2007), the increased mEPSC amplitude likely reflected the increased insertion of homomeric GluA1-containing AMPARs at CA1 neuron synapses (Das et al, 2008). If a small number of newly contributing GluA1 homomers with a higher conductance state (9-14 pS; Derkach et al, 1999) were inserted into the synapse, this might result in the small but significant increase in current amplitude without an observable change in the estimated conductance of native receptors in 1-day FZP-withdrawn compared with matched control rats (Benke et al, 1998; Spruston et al, 1995). Furthermore, the evidence suggests that CaMKII phosphorylation of GluA1 $\operatorname{Ser}^{831}$ was responsible for the near doubling of estimated channel conductance observed in neurons from 2-day FZP-withdrawn rats (Figure 6; Table 1).

Interestingly, in a model of CaMKII-mediated AMPAR recruitment, Guire et al (2008) calculated that for a typical CA1 hippocampal synapse containing $\sim 90$ GluA2-containing AMPARs, recruitment and phosphorylation of just four GluA1 homomers was sufficient to increase synaptic strength by $80 \%$. As the number of AMPAR at the CA1 PSD was estimated to be $\sim 58-70$ (Spruston et al, 1995), the $51-73 \%$ increase in synaptic strength associated with benzodiazepine withdrawal-anxiety would be consistent with the observed incorporation of GluA1 but not GluA2 subunits into CA1 neuron synapses (Das et al, 2008), and based on the latter model of AMPAR potentiation (Guire et al, 2008) would represent incorporation of just $\sim 2-3$ GluA1 homomeric receptors/synapse (Shen et al, 2009). Collectively, the functional data suggested that AMPAR potentiation may be modified in a stepwise manner during drug withdrawal, involving the progressive insertion of GluA1 homomers in 1-day FZP-withdrawn rats, possibly through PKA-mediated phosphorylation of $\mathrm{Ser}^{845}$ (Lee et al, 2010; He et al, 2009; Esteban et al, 2003; Song and Tietz, 2004), followed by enhanced GluA1 phosphorylation of $\mathrm{Ser}^{831}$ and a shift toward higher AMPAR conductance states on day 2 after withdrawal (Derkach et al, 1999; Esteban et al, 2003; Oh and Derkach, 2005).

To provide further insight into possible mechanisms by which AMPAR currents were potentiated during the withdrawal phase, the time course of GluA and CaMKII subunit expression patterns and their relevant phospho-analogs was evaluated in PSD-enriched subfractions of CA1 minislices. As GluA1 but not GluA2 or GluA3 subunit expression was enhanced (Figure 5; see also Izzo et al, 2001), the immunoblot findings were consistent with the hypothesis that GluA1 homomers were incorporated into CA1 neurons from 1-day FZP-withdrawn rats, leading to increased AMPAR current amplitude, similar to that observed with LTP (Lledo et al, 1995; Barria et al, 1997b; Benke et al, 1998; Plant et al, 2006; see also Adesnik and Nicoll, 2007). Interestingly, early LTP induced by theta-burst stimulation was not maintained in slices from 2-day FZP-withdrawn 
rats, though behavioral effects on novel object recognition and place and contextual memory were not observed (Shen et al, 2009). As AMPAR potentiation was also mutually occluded by CaMKII activation or tetanic stimulation (Lledo et al, 1995; Wang and Kelly, 1995), the latter finding further suggests that LTP- and drug-induced plasticity may share a similar downstream CaMKII-mediated pathways.

\section{Convergence/Divergence of Plasticity Models}

The mechanisms by which AMPAR currents are potentiated during drug withdrawal and with other models of activitydependent plasticity show numerous common features, with some notable dissimilarity. Unlike LTP, in which autophosphorylation of $\mathrm{Thr}^{286}$ leads to constitutive activation of CaMKII $\alpha$ without a change in total CaMKII $\alpha$ expression (Barria et al, 1997b; Lisman et al, 2002), pThr ${ }^{286}$-CaMKII levels remained unchanged in PSD-enriched subfractions derived from 1- or 2-day FZP-withdrawn rats. On the contrary, the total CaMKII $\alpha$ expression level was enhanced in all subcellular fractions from 2-day FZP-withdrawn rats (Figure 6), whereas CaMKII $\beta$ expression was unchanged in the PSD-enriched subfraction. Phosphorylation of $\mathrm{Ser}^{831}$ GluA1 in the face of enhanced CaMKII $\alpha$ levels suggests that CaMKII $\alpha$ levels in drug-withdrawn neurons might be autonomously activated through an alternate mechanism (eg binding to the GluN2B subunit) (Bayer et al, 2001, 2006). Notably, expression of withdrawal anxiety can be modulated in 2-day FZP-withdrawn rats through depression of NMDAR function (Van Sickle et al, 2002, 2004). Moreover, preliminary immunoblot and EM findings indicate that depression of NMDAR function involves a reduction in GluN1/GluN2B receptors at CA1 neuron synapses (Shen and Tietz, 2008; Das et al, 2010). Distinct from NMDAR-dependent LTP, in which $\mathrm{Ca}^{2+}$ influx primarily through NMDAR initiates CaMKII activation and AMPAR potentiation (Barria et al, 1997b; Collingridge et al, 2004), $\mathrm{Ca}^{2+}$ entry during benzodiazepine withdrawal may primarily occur through an increase in high voltageactivated $\mathrm{Ca}^{2+}$-channel current density (Katsura et al, 2007; Van Sickle et al, 2004; Xiang et al, 2008; Xiang and Tietz, 2007) and perhaps subsequently, through the increased density of $\mathrm{Ca}^{2+}$-permeable, GluA1 homomeric AMPARs (Das et al, 2008; Song et al, 2007).

The findings in benzodiazepine-withdrawn rats extend earlier studies, which reported that regulation of GluA1containing AMPARs plays a significant role in a variety of models of drug-induced plasticity associated with drug abuse (Loweth et al, 2010; Anderson et al, 2008; Kauer and Malenka, 2007; Boudreau and Wolf, 2005; Wolf et al, 2004; Sutton et al, 2003; Fitzgerald et al, 1996). GluA1 subunit alterations were detected in the mesolimbic dopamine reward system including prefrontal cortex and related limbic areas such as hippocampus and amygdala after withdrawal from repeated administration of a variety of drugs of abuse including opioids, cocaine, and ethanol (Ortiz et al, 1995; Glass et al, 2005, 2008; Ghasemzadeh et al, 2009; Edwards et al, 2009). For instance, behavioral sensitization, which develops during withdrawal from repeated cocaine administration, was recently associated with enhanced surface GluA1 expression in nucleus accumbens, without increased phospho-CaMKII $\alpha$ levels
(Boudreau et al, 2009), consistent with the observation that pThr ${ }^{286}$-CaMKII expression was unchanged during benzodiazepine withdrawal, despite enhanced GluA1 homomer $\mathrm{Ser}^{831}$ phosphorylation. Moreover, as in benzodiazepinewithdrawn rodents associated with signs of physical dependence (Katsura et al, 2007; Xiang et al, 2008), cocaine sensitization was also associated with an enhancement of $\mathrm{Ca}^{2+}$ entry through L-type voltage-gated $\mathrm{Ca}^{2+}$ channels (Nasif et al, 2005; Ford et al, 2009). Accordingly, the sources of $\mathrm{Ca}^{2+}$ entry during drug withdrawal, the resultant effect on CaMKII $\alpha$ activation, and, in turn, AMPAR potentiation in specific brain areas might in part explain the differences detected among models of activity-dependent and druginduced plasticity. That is, upstream mechanisms of CaMKII activation may differ between models of activitydependent plasticity resulting from brief, coincident activation of excitatory pathways, such as in LTP or fear conditioning (McKernan and Shinnick-Gallagher, 1997; Rodrigues et al, 2004) in comparison with drug-induced plasticity resulting from more persistent, selective activation of drug targets in specific neural circuits.

\section{ACKNOWLEDGEMENTS}

We thank Krista Pettee, Brian Behrle, Margarete Otting, and Eugene Orlowski for expert technical assistance. We also acknowledge LJ Greenfield, Jr MD PhD for critically reading the final manuscript. This work was supported by Department of Health and Human Services grant R01-DA18342 from the National Institute on Drug Abuse (NIDA) to E.I.T.; an individual predoctoral NRSA grant F30-DA06041 from NIDA to BJV; and predoctoral fellowships from the University of Toledo College of Medicine Biomedical Sciences Graduate Program (to GS and BJV). The National Institute of Drug Abuse Drug Supply Program supplied flurazepam.

\section{DISCLOSURE}

The authors declare that, except for income received from our primary employers, no financial support or compensation has been received from any individual or corporate entity over the past 3 years for research or professional service and there are no personal financial holdings that could be perceived as constituting a potential conflict of interest.

\section{REFERENCES}

Adesnik H, Nicoll RA (2007). Conservation of glutamate receptor 2-containing AMPA receptors during long-term potentiation. J Neurosci 27: 4598-4602.

Anderson SM, Famous KR, Sadri-Vakili G, Kumaresan V, Schmidt HD, Bass CE et al (2008). CaMKII: a biochemical bridge linking accumbens dopamine and glutamate systems in cocaine seeking. Nat Neurosci 11: 344-353.

Allison C, Pratt JA (2003). Neuroadaptive processes in GABAergic and glutamatergic systems in benzodiazepine dependence. Pharmacol Ther 98: 171-195.

Barria A, Derkach V, Soderling T (1997a). Identification of the $\mathrm{Ca}^{2+} /$ calmodulin-dependent protein kinase II regulatory phosphorylation site in the alpha-amino-3-hydroxyl-5-methyl-4- 
isoxazole-propionate-type glutamate receptor. J Biol Chem 272: 32727-32730.

Barria A, Muller D, Derkach V, Griffith LC, Soderling TR (1997b). Regulatory phosphorylation of AMPA-type glutamate receptors by CaM-KII during long-term potentiation. Science 276: 2042-2045.

Bateson AN (2002). Basic pharmacologic mechanisms involved in benzodiazepine tolerance and withdrawal. Curr Pharm Des 8: $5-21$.

Bayer KU, De Koninck P, Leonard AS, Hell JW, Schulman H (2001). Interaction with the NMDA receptor locks CaMKII in an active conformation. Nature 411: 801-805.

Bayer KU, LeBel E, McDonald GL, O'Leary H, Schulman H, De Koninck P (2006). Transition from reversible to persistent binding of CaMKII to postsynaptic sites and NR2B. J Neurosci 26: 1164-1174.

Benke TA, Luthi A, Isaac JT, Collingridge GL (1998). Modulation of AMPA receptor unitary conductance by synaptic activity. Nature 393: 793-797.

Boudreau AC, Ferrario CR, Glucksman MJ, Wolf ME (2009). Signaling pathway adaptations and novel protein kinase A substrates related to behavioral sensitization to cocaine. J Neurochem 110: 363-377.

Boudreau AC, Wolf ME (2005). Behavioral sensitization to cocaine is associated with increased AMPA receptor surface expression in the nucleus accumbens. J Neurosci 25: 9144-9151.

Collingridge GL, Isaac JT, Wang YT (2004). Receptor trafficking and synaptic plasticity. Nat Rev Neurosci 5: 952-962.

Collingridge GL, Olsen RW, Peters J, Spedding M (2009). A nomenclature for ligand-gated ion channels. Neuropharmacology 56: 2-5.

Das P, Lilly SM, Zerda R, Gunning III WT, Alvarez FJ, Tietz EI (2008). Increased AMPA receptor GluR1 subunit incorporation in rat hippocampal CA1 synapses during benzodiazepine withdrawal. J Comp Neurol 511: 832-846.

Das P, Zerda R, Alvarez FJ, Tietz EI (2010). Immunogold electron microscopic evidence of differential regulation of GluN1, GluN2A and GluN2B, NMDA-type glutamate receptor subunits in rat hippocampal CA1 synapses during benzodiazepine withdrawal. J Comp Neurol, (in press).

Derkach V, Barria A, Soderling TR (1999). $\mathrm{Ca}^{2+} /$ calmodulin-kinase II enhances channel conductance of alpha-amino-3-hydroxy-5methyl-4-isoxazolepropionate type glutamate receptors. Proc Natl Acad Sci USA 96: 3269-3274.

Derkach VA, Oh MC, Guire ES, Soderling TR (2007). Regulatory mechanisms of AMPA receptors in synaptic plasticity. Nat Rev Neurosci 8: 101-113.

Dunworth SJ, Stephens DN (1998). Sensitisation to repeated withdrawal, in mice treated chronically with diazepam, is blocked by an NMDA receptor antagonist. Psychopharmacology (Berl) 136: 308-310.

Edwards S, Graham DL, Whisler KN, Self DW (2009). Phosphorylation of GluR1, ERK, and CREB during spontaneous withdrawal from chronic heroin self-administration. Synapse 63: 224-235.

Esteban JA, Shi SH, Wilson C, Nuriya M, Huganir RL, Malinow R (2003). PKA phosphorylation of AMPA receptor subunits controls synaptic trafficking underlying plasticity. Nat Neurosci 6: 136-143.

Fitzgerald LW, Ortiz J, Hamedani AG, Nestler EJ (1996). Drugs of abuse and stress increase the expression of GluR1 and NMDAR1 glutamate receptor subunits in the rat ventral tegmental area: common adaptations among cross-sensitizing agents. J Neurosci 16: $274-282$.

Ford KA, Wolf ME, Hu XT (2009). Plasticity of L-type $\mathrm{Ca}^{2+}$ channels after cocaine withdrawal. Synapse 63: 690-697.

Gao L, Blair LA, Marshall J (2006). CaMKII-independent effects of KN93 and its inactive analog KN92: reversible inhibition of
L-type calcium channels. Biochem Biophys Res Commun 345: 1606-1610.

Gebhardt C, Cull-Candy SG (2006). Influence of agonist concentration on AMPA and kainate channels in CA1 pyramidal cells in rat hippocampal slices. J Physiol 573: 371-394.

Ghasemzadeh MB, Mueller C, Vasudevan P (2009). Behavioral sensitization to cocaine is associated with increased glutamate receptor trafficking to the postsynaptic density after extended withdrawal period. Neuroscience 159: 414-426.

Glass MJ, Kruzich PJ, Colago EE, Kreek MJ, Pickel VM (2005). Increased AMPA GluR1 receptor subunit labeling on the plasma membrane of dendrites in the basolateral amygdala of rats selfadministering morphine. Synapse 58: 1-12.

Glass MJ, Lane DA, Colago EE, Chan J, Schlussman SD, Zhou Y et al (2008). Chronic administration of morphine is associated with a decrease in surface AMPA GluR1 receptor subunit in dopamine D1 receptor expressing neurons in the shell and nonD1 receptor expressing neurons in the core of the rat nucleus accumbens. Exp Neurol 210: 750-761.

Griffiths RR, Johnson MW (2005). Relative abuse liability of hypnotic drugs: a conceptual framework and algorithm for differentiating among compounds. J Clin Psychiatry 66(Suppl 9): 31-41.

Guire ES, Oh MC, Soderling TR, Derkach VA (2008). Recruitment of calcium-permeable AMPA receptors during synaptic potentiation is regulated by CaM-kinase I. J Neurosci 28: 6000-6008.

Hayashi Y, Shi SH, Esteban JA, Piccini A, Poncer JC, Malinow R (2000). Driving AMPA receptors into synapses by LTP and CaMKII: requirement for GluR1 and PDZ domain interaction. Science 287: 2262-2267.

He K, Song L, Cummings LW, Goldman J, Huganir RL, Lee HK (2009). Stabilization of Ca2+-permeable AMPA receptor at perisynaptic sites by GluR1-S845 phosphorylation. Proc Natl Acad Sci USA 106: 20033-20038.

Hollmann M, Hartley M, Heinemann S (1991). $\mathrm{Ca}^{2+}$ permeability of KA-AMPA - gated glutamate receptor channels depends on subunit composition. Science 252: 851-853.

Ishida A, Kameshita I, Okuno S, Kitani T, Fujisawa H (1995). A novel highly specific and potent inhibitor of calmodulindependent protein kinase II. Biochem Biophys Res Commun 212: 806-812.

Izzo E, Auta J, Impagnatiello F, Pesold C, Guidotti A, Costa E (2001). Glutamic acid decarboxylase and glutamate receptor changes during tolerance and dependence to benzodiazepines. Proc Natl Acad Sci USA 98: 3483-3488.

Katsura M, Shibasaki M, Kurokawa K, Tsujimura A, Ohkuma S (2007). Up-regulation of L-type high voltage-gated calcium channel subunits by sustained exposure to 1,4- and 1,5benzodiazepines in cerebrocortical neurons. J Neurochem 103: 2518-2528.

Kauer JA, Malenka RC (2007). Synaptic plasticity and addiction. Nat Rev Neurosci 8: 844-858.

Koff JM, Pritchard GA, Greenblatt DJ, Miller LG (1997). The NMDA receptor competitive antagonist CPP modulates benzodiazepine tolerance and discontinuation. Pharmacology 55: 217-227.

Lee HK, Takamiya K, He K, Song L, Huganir RL (2010). Specific roles of AMPA receptor subunit GluR1 (GluA1) phosphorylation sites in regulating synaptic plasticity in the CA1 region of hippocampus. J Neurophysiol 103: 479-489.

Lerma J, Morales M, Ibarz JM, Somohano F (1994). Rectification properties and $\mathrm{Ca}^{2+}$ permeability of glutamate receptor channels in hippocampal cells. Eur J Neurosci 6: 1080-1088.

Lisman J, Schulman H, Cline H (2002). The molecular basis of CaMKII function in synaptic and behavioural memory. Nat Rev Neurosci 3: 175-190.

Lledo PM, Hjelmstad GO, Mukherji S, Soderling TR, Malenka RC, Nicoll RA (1995). Calcium/calmodulin-dependent kinase II and 
long-term potentiation enhance synaptic transmission by the same mechanism. Proc Natl Acad Sci USA 92: 11175-11179.

Llinas R, McGuinness TL, Leonard CS, Sugimori M, Greengard P (1985). Intraterminal injection of synapsin I or calcium/ calmodulin-dependent protein kinase II alters neurotransmitter release at the squid giant synapse. Proc Natl Acad Sci USA 82: 3035-3039.

Loweth JA, Singer BF, Baker LK, Wilke G, Inamine H, Bubula N et al (2010). Transient overxpression of alpha-Ca ${ }^{2+} /$ calmodulindependent protein kinase II in the nucleus accumbens shell enhances behavioral responding to amphetamine. J Neurosci 30: 939-949.

Lu W, Shi Y, Jackson AC, Bjorgan K, During MJ, Sprengel R et al (2009). Subunit composition of synaptic AMPA receptors revealed by a single-cell genetic approach. Neuron 62: 254-268.

Luthi A, Wikstrom MA, Palmer MJ, Matthews P, Benke TA, Isaac JT et al (2004). Bi-directional modulation of AMPA receptor unitary conductance by synaptic activity. BMC Neurosci 5: 44.

Mammen AL, Kameyama K, Roche KW, Huganir RL (1997). Phosphorylation of the alpha-amino-3-hydroxy-5-methylisoxazole4-propionic acid receptor GluR1 subunit by calcium/ calmodulin-dependent kinase II. J Biol Chem 272: 32528-32533.

Margrie TW, Rostas JA, Sah P (1998). Presynaptic long-term depression at a central glutamatergic synapse: a role for CaMKII. Nat Neurosci 1: 378-383.

McKernan MG, Shinnick-Gallagher P (1997). Fear conditioning induces a lasting potentiation of synaptic currents in vitro. Nature 390: 607-611.

Moga DE, Janssen WG, Vissavajjhala P, Czelusniak SM, Moran TM, Hof PR et al (2003). Glutamate receptor subunit 3 (GluR3) immunoreactivity delineates a subpopulation of parvalbumincontaining interneurons in the rat hippocampus. J Comp Neurol 462: 15-28.

Nasif FJ, Hu XT, White FJ (2005). Repeated cocaine administration increases voltage-sensitive calcium currents in response to membrane depolarization in medial prefrontal cortex pyramidal neurons. J Neurosci 25: 3674-3679.

Nicoll RA (2003). Expression mechanisms underlying long-term potentiation: a postsynaptic view. Philos Trans $R$ Soc Lond B Biol Sci 358: 721-726.

Oh MC, Derkach VA (2005). Dominant role of the GluR2 subunit in regulation of AMPA receptors by CaMKII. Nat Neurosci 8: 853-854.

Ortiz J, Fitzgerald LW, Charlton M, Lane S (1995). Biochemical actions of chronic ethanol exposure in the mesolimbic dopamine system. Synapse 21: 289-298.

Pellegrini-Giampietro DE (2003). An activity-dependent sperminemediated mechanism that modulates glutamate transmission. Trends Neurosci 26: 9-11.

Plant K, Pelkey KA, Bortolotto ZA, Morita D, Terashima A, McBain CJ et al (2006). Transient incorporation of native GluR2-lacking AMPA receptors during hippocampal long-term potentiation. Nat Neurosci 9: 602-604.

Poncer JC, Esteban JA, Malinow R (2002). Multiple mechanisms for the potentiation of AMPA receptor-mediated transmission by alpha- $\mathrm{Ca}^{2+} /$ calmodulin-dependent protein kinase II. J Neurosci 22: 4406-4411.

Rodrigues SM, Schafe GE, LeDoux JE (2004). Molecular mechanisms underlying emotional learning and memory in the lateral amygdala. Neuron 44: 75-91.

Sanhueza M, McIntyre CC, Lisman JE (2007). Reversal of synaptic memory by $\mathrm{Ca}^{2+} /$ calmodulin-dependent protein kinase II inhibitor. J Neurosci 27: 5190-5199.

Sans N, Vissel B, Petralia RS, Wang YX, Chang K, Royle GA et al (2003). Aberrant formation of glutamate receptor complexes in hippocampal neurons of mice lacking the GluR2 AMPA receptor subunit. J Neurosci 23: 9367-9373.
Seeburg PH (1996). The role of RNA editing in controlling glutamate receptor channel properties. J Neurochem 66: $1-5$.

Shen G, Tietz EI (2008). Regulation of synaptic NR2B subunitcontaining NMDA receptors: one component of glutamatergic plasticity in benzodiazepine withdrawal-anxiety. Soc Neurosci Abstr Program \# 662, Neuroscience Meeting Planner. Society for Neuroscience: Washington DC, 2008. Online.

Shen G, Van Sickle BJ, Tietz EI (2009). Positive allosteric activation of $\mathrm{GABA}_{\mathrm{A}}$ receptors bi-directionally modulates hippocampal glutamate plasticity and behavior. Biochem Soc Trans 37: 1394-1398.

Shen H, Gong QH, Aoki C, Yuan M, Ruderman Y, Dattilo M et al (2007). Reversal of neurosteroid effects at alpha4beta2delta $\mathrm{GABA}_{\mathrm{A}}$ receptors triggers anxiety at puberty. Nat Neurosci 10: 469-477.

Shen K, Teruel MN, Subramanian K, Meyer T (1998). CaMKIIbeta functions as an F-actin targeting module that localizes CaMKIIalpha/beta heterooligomers to dendritic spines. Neuron 21: 593-606.

Shi SH, Hayashi Y, Petralia RS, Zaman SH, Wenthold RJ, Svoboda $\mathrm{K}$ et al (1999). Rapid spine delivery and redistribution of AMPA receptors after synaptic NMDA receptor activation. Science 284: 1811-1816.

Song J, Shen G, Greenfield Jr LJ, Tietz EI (2007). Benzodiazepine withdrawal-induced glutamatergic plasticity involves up-regulation of GluR1-containing alpha-amino-3-hydroxy-5-methylisoxazole-4-propionic acid receptors in Hippocampal CA1 neurons. J Pharmacol Exp Ther 322: 569-581.

Song J, Tietz EI (2004). AMPA receptor plasticity in benzodiazepine-withdrawn rats is associated with only a transient increase in GluR1 subunit $\operatorname{Ser}^{845}$ phosphorylation in hippocampal CA1 neurons. Soc Neurosci Abstr Program No. 511.5, Neuroscience Meeting Planner. Society for Neuroscience: San Diego, CA, 2004. Online.

Spruston N, Jonas P, Sakmann B (1995). Dendritic glutamate receptor channels in rat hippocampal CA3 and CAl pyramidal neurons. J Physiol 482: 325-352.

Sutton MA, Schmidt EF, Choi KH, Schad CA, Whisler K, Simmons D et al (2003). Extinction-induced upregulation in AMPA receptors reduces cocaine-seeking behaviour. Nature 421: 70-75.

Swanson GT, Kamboj SK, Cull-Candy SG (1997). Single-channel properties of recombinant AMPA receptors depend on RNA editing, splice variation, and subunit composition. J Neurosci 17: 58-69.

Van Sickle BJ, Cox AS, Schak K, Greenfield Jr LJ, Tietz EI (2002). Chronic benzodiazepine administration alters hippocampal CA1 neuron excitability: NMDA receptor function and expression(1). Neuropharmacology 43: 595-606.

Van Sickle BJ, Tietz EI (2002). Selective enhancement of AMPA receptor-mediated function in hippocampal CA1 neurons from chronic benzodiazepine-treated rats. Neuropharmacology 43: 11-27.

Van Sickle BJ, Xiang K, Tietz EI (2004). Transient plasticity of hippocampal CA1 neuron glutamate receptors contributes to benzodiazepine withdrawal-anxiety. Neuropsychopharmacology 29: 1994-2006.

Wafford KA (2005). GABA-A receptor subtypes: any clues to the mechanism of benzodiazepine dependence? Curr Opin Pharmacol 5: 47-52.

Wang JH, Kelly PT (1995). Postsynaptic injection of $\mathrm{Ca}^{2+} / \mathrm{CaM}$ induces synaptic potentiation requiring CaMKII and PKC activity. Neuron 15: 443-452.

Washburn MS, Dingledine R (1996). Block of alpha-amino-3hydroxy-5-methyl-4-isoxazolepropionic acid (AMPA) receptors by polyamines and polyamine toxins. J Pharmacol Exp Ther 278: 669-678. 
Wenthold RJ, Petralia RS, Blahos II J, Niedzielski AS (1996). Evidence for multiple AMPA receptor complexes in hippocampal CA1/CA2 neurons. J Neurosci 16: 1982-1989.

Wolf ME, Sun X, Mangiavacchi S, Chao SZ (2004). Psychomotor stimulants and neuronal plasticity. Neuropharmacology 47: 61-79.

Xiang K, Earl DE, Davis K, Giovannucci DR, Greenfield Jr LJ, Tietz EI (2008). Chronic benzodiazepine administration potentiates high voltage-activated calcium currents in hippocampal CA1 neurons. J Pharmacol Exp Ther 327: 872-883.

Xiang K, Tietz EI (2007). Benzodiazepine-induced hippocampal CA1 neuron alpha-amino- hydroxy-5-methylisoxasole-4-propio- nic acid (AMPA) receptor plasticity linked to severity of withdrawal anxiety: differential role of voltage-gated calcium channels and N-methyl-D-aspartic acid receptors. Behav Pharmacol 18: 447-460.

Zeng X, Tietz EI (1999). Benzodiazepine tolerance at GABAergic synapses on hippocampal CA1 pyramidal cells. Synapse 31: 263-277.

Zhu JJ, Esteban JA, Hayashi Y, Malinow R (2000). Postnatal synaptic potentiation: delivery of GluA4-containing AMPA receptors by spontaneous activity. Nat Neurosci 3: 1098-1106. 